OESOPHAGEAL DISEASE

\title{
Intragastric maldistribution of a liquid meal in patients with reflux oesophagitis assessed by three dimensional ultrasonography
}

\author{
S Tefera, O H Gilia, E Olafsdottir, T Hausken, J G Hatlebakk, A Berstad
}

See end of article for authors' affiliations

Correspondence to Dr S Tefera, Medical Department, Haukeland Hospital, University of Bergen, N-5021 Bergen, Norway;

stef@haukeland.no

Accepted for publication 14 May 2001

\begin{abstract}
Background and aims: Our aim was to study intragastric volume and distribution of a liquid meal in patients with reflux oesophagitis using three dimensional ultrasonography.

Methods: Twenty patients and 20 healthy controls underwent ultrasonographic measurements of the stomach using a position sensor based on magnetic scanhead tracking for acquisition of three dimensional images. In vivo accuracy of the method was evaluated by scanning a soup filled barostat bag positioned in the proximal stomach of six healthy subjects.

Results: In the volume range 100-700 ml, our three dimensional system showed excellent correlation ( $r=0.99$ ) between estimated and true volumes (limits of agreement -3.4 to $11.0 \mathrm{ml}$ ) and a low interobserver variation (limits of agreement -10.9 to $6.7 \mathrm{ml}$ ). After ingestion of a $500 \mathrm{ml}$ meat soup meal, patients with reflux oesophagitis revealed a larger volume of the total and proximal stomach at two and 10 minutes $(p=0.05 ; p=0.01$, respectively), and an increased proximal/distal intragastric volume ratio at 10 minutes $(p=0.04)$. Patients also experienced more epigastric fullness than controls $(p=0.0006)$. Conclusions: The present three dimensional ultrasound system showed excellent agreement with true volumes and low interobserver variation. Soon after a liquid meal, patients with reflux oesophagitis have abnormal pooling of the ingested liquid in the proximal stomach.
\end{abstract}

G astro-oesophageal reflux disease (GORD) is a multifactorial disease caused by abnormal exposure of the oesophagus to the gastric contents. ${ }^{1}$ Gastric distension is one of the mechanisms that may contribute to postprandial gastro-oesophageal reflux,,$^{2-4}$ and recent studies have suggested abnormal proximal gastric motor function in patients with reflux oesophagitis. In one study, the gastric pressure response to distension was reduced in fasting patients with GORD. ${ }^{5}$ Others, using a gastric barostat, have reported postprandial gastric relaxation to be abnormally pronounced ${ }^{6}$ or prolonged. ${ }^{7}{ }^{8}$ Scintigraphic studies have showed delayed gastric emptying in a subgroup of GORD patients. ${ }^{7}{ }^{10}$ In a previous study using transabdominal two dimensional real time ultrasonography in patients with reflux oesophagitis, we found a larger sagittal area of the proximal stomach associated with the perception of epigastric fullness soon after a meal. ${ }^{11}$

Table 1 Demographic data for healthy controls and patients with mild or moderate reflux oesophagitis scanned using a three dimensional ultrasonographic system

\begin{tabular}{|c|c|c|c|}
\hline & $\begin{array}{l}\text { Healthy } \\
\text { subjects }\end{array}$ & Patients & p Value \\
\hline No patients & 20 & 20 & NS \\
\hline Male/female ratio & $7 / 13$ & $7 / 13$ & NS \\
\hline Age (y) (mean (range)) & $43(27-62)$ & $42(25-57)$ & NS \\
\hline Weight (kg) (mean (SD)) & $69.9(12.3)$ & $83.2(8.9)$ & 0.0004 \\
\hline Height $(\mathrm{cm})$ (mean (SD)) & $171.8(10.0)$ & $176.2(9.4)$ & NS \\
\hline Body mass index $\left(\mathrm{kg} / \mathrm{m}^{2}\right)$ & $23(19-28)$ & $27(20-38)$ & 0.003 \\
\hline Oesophagitis grade I/II & - & $14 / 6$ & - \\
\hline Hiatal hernia (n) & - & 10 & - \\
\hline Mean length of hiatal hernia $(\mathrm{cm})$ & - & 2.9 & - \\
\hline
\end{tabular}

Both the barostat and ultrasonographic results suggested an abnormal gastric accommodation to a meal in patients with GORD.

Barostat studies measure gastric tone, from which one can infer information on gastric accommodation. However, neither barostat nor scintigraphy can assess gastric volumes postprandially. Scintigraphic methods do not allow determination of intragastric volume. Using three dimensional ultrasound with a magnetic scanhead tracking system, Gilja and colleagues $^{12}$ showed excellent in vitro accuracy in volume estimation of porcine stomach volumes, and calculated gastric emptying rates of a healthy human stomach more precisely than by two dimensional ultrasound.

The objective of this study was to investigate more precisely intragastric volume and distribution of a liquid meal in patients with reflux oesophagitis using this new non-invasive three dimensional ultrasound method.

\section{MATERIALS AND METHODS}

\section{Patients}

The study group consisted of 20 consecutive patients (seven men and 13 women) with chronic heartburn in whom a diagnosis of reflux oesophagitis had recently been made at endoscopy. None of the patients were using $\mathrm{H}_{2}$ receptor antagonists or proton pump inhibitors. Twenty healthy controls (seven men and 13 women), mainly from the staff at the hospital, were recruited as a control group. Patients had a slightly higher body mass index (BMI) than healthy controls $(\mathrm{p}=0.003)$; otherwise the groups were comparable (table 1$)$. Six healthy subjects (two men and four women; mean age 29

Abbreviations: $\mathrm{BMI}$, body mass index; $\mathrm{CV}$, coefficient of variation; GORD, gastro-oesophageal reflux disease; POM, position and orientation measurement; VAS, visual analogue scale. 
years, range 23-41) were included for in vivo validation of the method (see below).

Reasons for exclusion from the study were finding of a hiatial hernia larger than $5 \mathrm{~cm}$, signs of disease other than reflux oesophagitis grade I or II (for example, scleroderma, peptic stricture, serious systemic or suspect malignant disease, previous gastric surgery, previous peptic ulcer disease, Helicobacter pylori infection, alcoholism, disease of the liver, pancreas, and bile ducts), pregnancy or nursing women, or need for drug therapy that might influence gastric motor function.

\section{Endoscopy}

The severity of macroscopic oesophagitis was graded according to the Berstad classification as follows: 0, normal; I, red streaks or spots along the ridge of the mucosal folds, with or without fibrinous exudate; II, broded lesions, each involving the entire width of a fold or coalescing into fields of erythema, with or without fibrinous exudate; III, stricture or endoscopically visible ulcer in the distal esophagus. ${ }^{13}$ Grade I is equivalent to Los Angeles classification A and B, whereas grade II is equivalent to grades $\mathrm{C}$ and $\mathrm{D}$. A hiatal hernia was defined as gastric folds seen at least $2 \mathrm{~cm}$ above the diaphragm. H pylori status was established by rapid urease test. ${ }^{14}$

\section{Three dimensional ultrasound}

The three dimensional imaging system consisted of a commercially available ultrasound scanner (System Five, GE Vingmed Ultrasound, Horten, Norway) with a built in magnetometer based position and orientation measurement (POM) device (Flock of Birds Model 6D FOB; Ascension Technology Corp., Burlington, Vermont, USA). The POM system is based on a transmitter, which produces a spatially varying magnetic field, and a small receiver containing three orthogonal coils to sense the magnetic field strength. ${ }^{15}$ A detailed description of the POM system and the calibration procedure has been reported previously. ${ }^{12}$ A $3.5 \mathrm{MHz}$ broadband curvilinear transducer was used with the snap-on POM sensor firmly attached to it. Data storage was first done on System Five and at the end of examination was transferred to a 1.3 GB magnetic optic disk via a standard ethernet network. Data processing was done on a Windows-NT version 4.0 workstation (Compac Proline 100 MHZ Pentium, San Jose, California, USA) equipped with 64 MB RAM.

\section{Protocol}

Patients returned for ultrasound scanning within seven days after endoscopy. Smoking was not allowed before the examination, which was done between $8.00 \mathrm{am}$ and $10.00 \mathrm{am}$ after an overnight fast. Participants were scanned while sitting in a wooden chair, leaning slightly backward at an angle of $120^{\circ}$ between the thighs and the spine. The end of soup ingestion was defined as time zero, and scanning was performed postprandially immediately after a four minute ingestion period of the test meal, and after 10, 20, and $30 \mathrm{~min}$ utes. Occurrence of antral contractions was observed for at least three minutes before ingestion of the test meal to evaluate whether the subject's interdigestive migrating motor complex was in phase III (regular contraction with a frequency of $3 / \mathrm{min}$ ). If phase III was observed, ingestion of the test meal was postponed until phase I (quiescence) was again observed.

\section{Test meal}

A commercial meat soup ( $500 \mathrm{ml}$ of Toro clear meat soup; Rieber $\&$ Søn A/S, Bergen, Norway) which contains $1.8 \mathrm{~g}$ protein, $0.9 \mathrm{~g}$ fat, and 1.1 carbohydrate $(20 \mathrm{kcal})$ at a temperature of $37^{\circ} \mathrm{C}$ was ingested over a period of four minutes (during ultrasound scanning). The $\mathrm{pH}$ of the soup was between 5.4 and 5.7 and osmolarity was $350 \mathrm{mosmol} / \mathrm{kg} \mathrm{H}_{2} \mathrm{O}$. The soup meal induced antral contractions at a frequency of $3 / \mathrm{min}$ (fed state) in more than $85 \%$ of patients with functional dyspepsia and healthy controls. ${ }^{16} 17$

\section{Data acquisition}

Using this three dimensional system, only one investigator (ST) was needed to perform all of the procedures, and to scan and run the image workstation. The depth of scanning was adjusted to fit each individual's body, with an average of 20 $\mathrm{cm}$. The stomach was scanned at the end of normal expiration using a standardised scanning pattern, starting in the proximal end where the transducer was positioned by the left subcostal margin and then moved distally to the gastroduodenal junction. If a gastric contraction was observed, scanning was paused until the contraction wave passed the position of the image sector. For each scan, approximately 60-70 ultrasound images were stored, with a scan typically lasting 6-7 seconds. The stored images were then transferred to the magnetic optic disk. To assess the problem of air pockets in the stomach, the visible amount of air was graded as: 0 , visible air in the fundus; 1 , small amounts; 2 , moderate amounts; and 3, great amounts of air, necessitating exclusion from the study.

\section{Volume estimation}

For volume estimation, we used a designated software package with rendering and volume estimation capability (EchoPAC-3D; GE Vingmed Sound, Horten, Norway). ${ }^{18}$ The program accepted three dimensional image data acquisition with both mechanically controlled probes and freehand movement using the integrated POM system. On the workstation, the raw data (original scanplanes) were used for volume estimation. The volume estimation algorithm was previously evaluated and demonstrated good agreement with true in vitro volumes and in vivo magnetic resonance imaging volumes, as well as low intra and interobserver errors. ${ }^{12}{ }^{19}{ }^{20} \mathrm{In}$ the volume reconstruction windows, the end point of the organ was carefully marked and closed, thereafter the outer contour of the organ of the middle frames were traced. The inner echogenic layer of the stomach, corresponding to the interface between the soup and the mucosa of the gastric wall, was outlined. ${ }^{21}$ For intermediate frames, the program is capable of drawing contours automatically generated by a triangulation technique..$^{20}$ Manually traced organ contours automatically upgrade the intermediate frames and also the volume estimate. The examiner can therefore by visual inspection check if the manually drawn and automatically generated contours give a satisfactorily representation of the stomach, and if necessary add new manually drawn contours. An average of 18-25 tracings were needed to complete the stomach's contour through the 60-70 frames. Anyplane window was used to check the accuracy of the contours in planes $90^{\circ}$ to the plane used for manual tracing. From a three dimensional reconstructed stomach, the proximal and distal parts were separated by a vertical slice from the incisura angularis at the lesser gastric curvature sagittally towards the greater curvature. In cases where it was impossible to find the incisura angularis, the decision as to where to separate the distal from the proximal stomach was made during data analysis. The most proximally observed antral circular outline corresponds to the vertical division of the incisura angularis. The time needed for manual tracing and one volume estimation of the whole stomach was approximately $10-15$ minutes. This procedure was performed on the workstation four months after the scanning was done and the investigator was blinded to the participant's identity and to the order of the images.

\section{In vivo validation}

A bag similar to that used for barostat studies was utilised for in vivo validation of the three dimensional ultrasound system. The bag had a maximal volume of $750-800 \mathrm{ml}$ and was sealed 
to the end of a $120 \mathrm{~cm}$ long $16 \mathrm{~F}$ diameter single lumen polyvinyl tube. The length of the empty bag measured $20 \mathrm{~cm}$ and maximum diameter was $22 \mathrm{~cm}$. The deadspace of the tube had a volume of $10 \mathrm{ml}$. After removing the air, the bag was folded around the distal end of the tube and smeared with lidocaine gel before it was introduced orally into the stomach. Subjects received only local anaesthesia (lidocaine) applied to the oropharynx and no sedation. After introducing the bag into the stomach, it was unfolded by injecting $700 \mathrm{ml}$ of air manually through the tube and pulling it until resistance was observed. In this way the bag was positioned in the proximal stomach just inferior to the diaphragm. After placing the bag in the proximal stomach, the air was removed. To prevent the air coming into the bag, the tube was clamped at the top end. Using a syringe, in steps of $100 \mathrm{ml}$, up to $700 \mathrm{ml}$ of meat soup were instilled into and subsequently aspirated from the barostat bag before each three dimensional scan took place. After the last scan at $100 \mathrm{ml}$, the bag was removed and controlled to confirm that no leakage had occurred. Each subject was scanned twice.

\section{Symptom evaluation}

Subjects were asked to score abdominal symptoms using a visual analogue scale (VAS) for each symptom (pain, discomfort, nausea, epigastric fullness and hunger, or satiety). ${ }^{22-24}$ Scoring was done on a $10 \mathrm{~cm}$ long line where 0 denotes no symptom present and $10 \mathrm{~cm}$ an intolerable symptom. Registration was performed immediately before the meal and five minutes after the meal. Patients were asked to score the actual state of their symptom perception.

\section{Statistics}

All calculations and graphic designs were performed using commercially available computer software (Graphpad Prism; GraphPad software Inc, San Diego, California, USA). Measurements are given as mean (SD) if not otherwise stated. If the data appeared normally distributed, the Student's $t$ test with two sided probabilities was used to compare the statistical significance of differences and the distribution of data between groups. If the data were not normally distributed, a non-parametric test was applied. As an initial measure of association between estimated and true volume of the barostat bag, Pearson's correlation coefficient was determined. Limits of agreement were estimated as suggested by Bland and Altman. ${ }^{25}$ The per cent error of the measurements was defined as ((estimated volume-true volume)/true volume $\times 100 \%$. Linear regression analysis was applied to estimate gastric emptying rates and half emptying times. A p value $\leqslant 0.05$ was chosen as the level of statistical significance.

\section{Ethics approval}

The study was approved by the regional ethics committee and was conducted in accordance with the revised Declaration of Helsinki. All volunteers gave written informed consent to participate.

\section{RESULTS}

The magnetic position sensor and transmitter system for acquisition of three dimensional ultrasonograms was applicable for in vivo imaging of the human stomach. Neither the transmitter nor the scanhead sensor mount and wiring interfered with the scanning procedure.

\section{In vivo validation}

A total of 156 three dimensional images were recorded. Due to crossing of manually traced organ contours, difficulties in upgrading of the intermediate frames, or poor image visualisation a total of eight of 156 images (5.1\%) were excluded. The three dimensional system yielded an excellent correlation $(r=0.99 ; \mathrm{p}<0.0001)$ between true and estimated

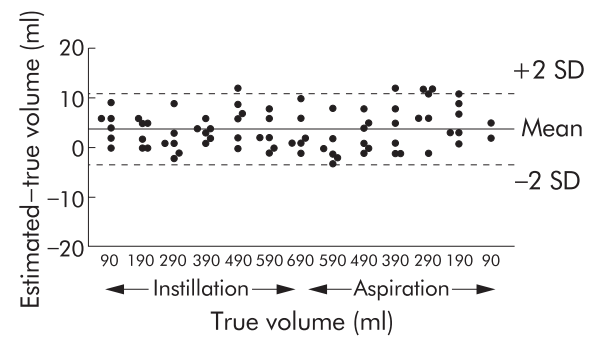

Figure 1 Plot displaying limits of agreement in volume estimation by ultrasonography and magnetic scanhead tracking of a barostat bag within the stomach of six healthy volunteers. The mean difference was $3.8 \mathrm{ml}$ and the limits of agreement were -3.4 to 11.0 $\mathrm{ml}$ in the volume range $100-700 \mathrm{ml}$.

volumes. There was no correlation between true volumes and absolute values of the difference between estimated and true volumes $(r=-0.29 ; \mathrm{p}=0.34)$ or interobserver difference $(r=-0.22 ; \mathrm{p}=0.47)$. The mean difference between true and estimated volumes was 3.8 (3.6) $\mathrm{ml}$ and the limits of agreement were -3.4 to $11.0 \mathrm{ml}$ in the range $100-700 \mathrm{ml}$ (fig 1). The error over the entire volume range was, on average, 1.6 (1.5)\%. The average interobserver difference of the estimated volume was $-2.1(4.4) \mathrm{ml}$, and the limits of agreement were -10.9 to $6.7 \mathrm{ml}$. There was no significant difference between the estimated volumes of the three dimensional images obtained by four different operators.

\section{Scanning of patients and healthy controls}

None of the patients or healthy controls was excluded due to air pockets in the gastric fundus, technical difficulties, or symptoms. Due to crossing of manually traced organ contours, difficulties in upgrading of the intermediate frames, or poor image visualisation, a total of six of 80 images (two after 10 minutes, one after 20 minutes, and three after 30 minutes) from healthy controls and two of 80 images (two after 20 minutes) from patients were excluded. Prior to soup ingestion, no fluids were visualised in the proximal stomach in patients or controls when seated. Postprandially, during the scanning, gastric contractions were not observed in the image sector. In two patients it was impossible to find the incisura angularis and the decision as to where to separate the distal from the proximal stomach was made during data analysis. A total of eight patients (three grade 2 and five grade 1 ) and five healthy controls (two grade 2 and three grade 1 ) had visible air pockets in the gastric fundus.

The presence and degree of air pockets in the gastric fundus, separation of the distal from the proximal stomach, or exclusion of images due to poor image visualisation did not significantly influence the results. The greater BMI in the reflux patients could presumably create difficulties for ultrasound scanning. However, we found no differences in the applicability of our three dimensional method between patients and controls.

\section{Gastric volumes and emptying}

Reflux oesophagitis patients revealed a larger volume for the total and proximal stomach at two minutes $(\mathrm{p}=0.05$ and $p=0.03$, respectively) and at 10 minutes $(p=0.01$ and $\mathrm{p}=0.006$, respectively) postprandially compared with healthy controls (table 2, fig 2). Intragastric distribution of the liquid meal, expressed as proximal to distal volume, ranged on average from 6.1 (3.2) to 2.9 (2.9) in patients, and from $5.0(2.3)$ to 3.9 (4.8) in healthy controls at two and 30 minutes postprandially, respectively. At 10 minutes, there was significant increased pooling of the meal in the proximal stomach in patients compared with healthy controls postprandially $(4.8$ (2.9) $v 3.2(1.5) ; \mathrm{p}=0.04)$

Variability (coefficient of variation, CV) in total gastric volumes in patients with reflux oesophagitis was in the range 
Table 2 Volumes of the stomach estimated by three dimensional ultrasonography in 20 healthy controls and 20 patients with mild or moderate reflux oesophagitis

\begin{tabular}{|c|c|c|c|}
\hline $\begin{array}{l}\text { Postprandial } \\
\text { scanning }\end{array}$ & Healthy controls (ml) & Patients (ml) & $p$ Value \\
\hline \multicolumn{4}{|l|}{$2 \min$} \\
\hline Proximal & $266.9(45.5)(269.6)$ & $312.7(79.6)(319.5)$ & 0.03 \\
\hline Distal & $64.5(30.3)(53.6)$ & $61.0(25.5)(56.8)$ & 0.69 (N \\
\hline Total & 330.9 (51.5) (351.0) & $374.2(78.6)(377.3)$ & 0.05 \\
\hline \multicolumn{4}{|l|}{$10 \mathrm{~min}$} \\
\hline Proximal & 149.2 (52.9) (132.9) & $209.3(72.4)(201.1)$ & 0.006 \\
\hline Distal & $54.2(23.6)(46.5)$ & $56.78(33.4)(46.1)$ & 0.79 (1) \\
\hline Total & 203.4 & ) (276.1) & 0.01 \\
\hline \multicolumn{4}{|c|}{$20 \min$} \\
\hline Proximal & 100.0 & ) (1 19.3) & 0.09 (NS) \\
\hline Distal & 40.1 (19.7) (34.8) & $45.3(25.6)(39.5)$ & 0.49 (NS) \\
\hline Total & $139.5(50.8)(128.7)$ & $171.8(68.7)(159.5)$ & 0.11 (NS) \\
\hline \multicolumn{4}{|l|}{$30 \mathrm{~min}$} \\
\hline Proximal & $60.7(28.9)(55.9)$ & $69.9(34.4)(64.8)$ & 0.39 (NS) \\
\hline Distal & 27.7 (16.7) (28.9) & $35.2(22.7)(31.3)$ & 0.27 (NS) \\
\hline Total & $88.4(41.0)(84.8)$ & $105.1(48.4)(103.4)$ & $0.27(\mathrm{NS})$ \\
\hline
\end{tabular}

Values are mean (SD) (median).

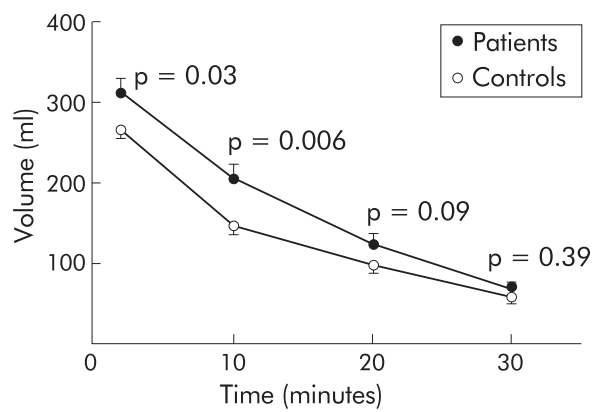

Figure 2 Proximal gastric volume estimated by three dimensional ultrasonography in 20 healthy controls and 20 patients with mild or moderate reflux oesophagitis following ingestion of a $500 \mathrm{ml}$ soup meal. Patients with reflux oesophagitis revealed a larger volume of the proximal stomach at two and 10 minutes postprandially compared with healthy controls. Values are mean (SEM).

$21 \%$ (two minutes) to $46 \%$ (30 minutes), showing increasing variability with emptying time $(r=-0.99 ; \mathrm{p}=0.005$ between $\mathrm{CV}$ and mean time volume), while in healthy controls it was in the range $16 \%$ (two minutes) to $46 \%$ (30 minutes), also showing similar increasing variability with emptying time ( $r=-0.99 ; \mathrm{p}=0.009$ between $\mathrm{CV}$ and mean time volume). The average half emptying time of this liquid meal was 20.8 (5.2) minutes for the patient group and 21.2 (9.9) minutes for controls $(\mathrm{p}=0.88)$.

\section{Symptoms}

Preprandial pain and discomfort were slightly but significantly more pronounced in patients than in controls. In the postprandial period, both groups experienced epigastric fullness but significantly more so in patients (table 3 ). Comparison of delta values (post minus preprandial scores) for epigastric fullness showed a significant difference between the two groups $(\mathrm{p}=0.02)$. There was no significant correlation between postprandial epigastric fullness and proximal stomach volume. None of the patients experienced heartburn during the experiment.

\section{DISCUSSION}

In this study, three dimensional ultrasound imaging was used for the first time for investigation of intragastric volume and distribution of a meal in patients with reflux oesophagitis. Compared with healthy controls, patients revealed a larger volume of the proximal stomach at two and 10 minutes, and showed an abnormally high proximal/distal stomach ratio 10 minutes after the meal. Patients also experienced more epigastric fullness after the meal than healthy controls. These patients had, on average, a greater BMI than healthy controls. However, postprandial fullness, proximal gastric volume, or intragastric distribution were not correlated with BMI. Hence we do not believe that differences in BMI can explain the differences in postprandial fullness and volumes between patients with GORD and healthy controls. Neither was the degree of oesophagitis or the presence of a hiatial hernia related to the above results.

Consistent with our finding, Penagini and colleagues ${ }^{7}$ found abnormal retention of a liquid meal in the proximal stomach of patients with reflux oesophagitis using scintigraphy even though overall gastric emptying was normal. The mechanisms responsible for retention of the meal in the proximal stomach in patients with reflux oesophagitis may be related to abnormal wall relaxation, as shown by the gastric barostat. ${ }^{5-8}$ Some patients with reflux oesophagitis may have impaired vagal function. ${ }^{26}$ However, the finding of early postprandial retention of a liquid meal in the proximal stomach is unexpected in the presence of vagal impairment as after truncal vagotomy initial gastric emptying of liquid is rapid, ${ }^{27}{ }^{28}$ and in patients with diabetic vagal neuropathy the proximal stomach is small and meal induced gastric relaxation is impaired. ${ }^{29}$

Contrary to the small proximal stomach in functional dyspepsia patients, patients with GORD have a relatively larger proximal stomach soon after a meal. ${ }^{30}$ Both patient groups experience epigastric fullness suggesting increased gastric wall tension. $^{31}$ However, in contrast with patients with functional dyspepsia, patients with GORD in addition to the perception of fullness also experience heartburn. If the wide proximal stomach is caused by pressure within (that is, distension), mechanoreceptors of the subcardial area may be activated and the frequency of transient lower oesophageal sphincter relaxations thereby increased. ${ }^{2}{ }^{32}$ The perception of

Table 3 Symptom scores assessed on a $10 \mathrm{~cm}$ visual analogue scale before and after a test meal in 20 healthy controls and 20 patients with mild or moderate reflux oesophagitis

\begin{tabular}{llllllll}
\hline & \multicolumn{2}{l}{ Fasting $(\mathrm{cm})$} & & \multicolumn{2}{l}{ Postprandial $(\mathrm{cm})$} \\
\cline { 2 - 3 } Symptoms & Controls & Patients & $\mathrm{p}$ Value & & Controls & Patients & $\mathrm{p}$ Value \\
\hline Pain & $0.1(0.2)$ & $0.7(1.1)$ & 0.02 & & $0.2(0.2)$ & $0.7(1.4)$ & $\mathrm{NS}$ \\
Nausea & $0.3(1.0)$ & $0.6(0.9)$ & $\mathrm{NS}$ & & $0.9(1.7)$ & $1.0(1.8)$ & $\mathrm{NS}$ \\
Fullness & $0.3(0.7)$ & $1.2(1.8)$ & 0.07 & & $1.6(1.4)$ & $3.8(2.2)$ & 0.0006 \\
Discomfort & $0.4(0.9)$ & $1.7(1.6)$ & 0.005 & & $0.9(1.4)$ & $1.7(1.8)$ & $\mathrm{NS}$ \\
Hunger/satiety & $2.7(2.1)$ & $3.0(2.3)$ & $\mathrm{NS}$ & & $5.4(2.3)$ & $5.5(2.4)$ & $\mathrm{NS}$ \\
\hline
\end{tabular}


fullness in the presence of a large proximal gastric volume suggests that the proximal stomach is distended and not only abnormally relaxed soon after a meal. Hence the abnormal early filling of the proximal stomach may represent an important pathogenetic mechanism in reflux oesophagitis.

In our previous study, using a two dimensional ultrasound system, we found a correlation between postprandial fullness and sagittal area of the most proximal part of the stomach. In the present study, we could not confirm a significant correlation between fullness and volume of the stomach proximal to the incisura angularis. The perception of epigastric fullness may be related more to gastric wall tension than to intragastric volume. ${ }^{31}$ We measured volumes only and not pressures, and we were unable to calculate gastric wall tension. Nevertheless, depending on the degree of relaxation, both the perception of fullness and the experience of heartburn may be consequences of increased pooling of a meal in the proximal stomach during the early postprandial period.

Our finding of a significantly increased proximal to distal intragastric volume ratio at 10 minutes but not at two minutes postprandially could be due to redistribution of the meal from the distal to the proximal stomach. The mechanism behind this possible redistribution is unclear. Behar and Ramsby showed that the number of antral contractions and cumulative antral activity were lower in reflux oesophagitis patients than in controls. ${ }^{33}$ In this study, the average half emptying time of the ingested meal in healthy controls (21.2 (9.9) minutes) was close to that previously found ${ }^{12}$ by the same three dimensional ultrasound system (22.1 (3.8) minutes) or by scintigraphy (22.9 (12.1) minutes). ${ }^{34}$ Because total gastric emptying was normal in our GORD patients, it is tempting to speculate that the abnormal widening of the proximal stomach 10 minutes after ingestion of a meal may be the result of intragastric redistribution with reflux of ingested material from the antrum and even from the duodenum back to the proximal stomach.

Scintigraphy, the gold standard for the study of gastric emptying, is also applicable for studying intragastric distribution of a meal. However, this method does not allow determination of intragastric volumes. It involves a radiation hazard and can be performed only with certain types of meals. Volume visualisation methods such as magnetic resonance imaging, computed tomography, single photon emission computed tomography, and position emission tomography have all been available for some time ${ }^{35}$ but these techniques have not achieved extensive clinical use because of the high cost and time required to obtain and process high resolution image data.

In vitro validation of our ultrasound system using a position sensor based on magnetic scanhead tracking demonstrated high accuracy and low interobserver variation. ${ }^{12}{ }^{36}$ The present in vivo validation of this system showed excellent agreement with true volumes and low interobserver variation. There are two magnetic positioning devices of sufficient quality available for three dimensional ultrasound imaging: Fastrak (3Space Devices; Polhemus, Colchester, Vermont, USA) and Flock of Birds (Ascension Technologies Corp., Burlington, Vermont, USA). These devices have been used successfully in echocardiography, obstetrics, and vascular imaging, and considerable experience has been generated. We might be the only centre using the Bird system for gastric volume estimation. To assess the true reproducibility of such a complex technique with investigators with varying experience, a multicentre study is warranted.

In conclusion, patients with GORD have an abnormally large volume of the proximal stomach soon after a liquid meal, concomitant with the perception of fullness. The abnormal filling of the proximal stomach may represent an important pathogenetic mechanism in reflux oesophagitis.

\section{ACKNOWLEDGEMENT}

This study was supported by Innovest Strategic Research Program (Haukeland University Hospital and University of Bergen), Bergen, Norway.

\section{Authors' affiliations}

S Tefera, O H Gilia, T Hausken, J G Hatlebakk, A Berstad, Division of Gastroenterology, Institute of Medicine, Haukeland Hospital, University of Bergen, Norway

E Olafsdottir, Division of Gastroenterology, Institute of Paediatrics, Haukeland Hospital, University of Bergen, Norway

\section{REFERENCES}

1 Dodds WJ, Dent J, Hogan WJ, et al. Mechanisms of gastrooesophageal reflux in patient with reflux oesophagitis. $N$ Engl J Med 1982;307: 1547-52.

2 Holloway RH, Hongo M, Berger K, et al. Gastric distention: a mechanism for postprandial gastroesophageal reflux. Gastroenterology 1985:89:779-84.

3 Franzi SJ, Martin CJ, Cox MR, et al. Response of canine lower oesophageal sphincter to gastric distention. Am J Physiol 1990;259:G380-5

4 Wyman JB, Dent J, Heddle R, et al. Control of belching by the lower oesophageal sphincter. Gut 1990:31:639-46.

5 Hartley MN, Walker SJ, Mackie CR. Abnormal gastric adaptive relaxation in patients with gastrooesophageal reflux. Gut 1990;31:500-3.

6 Zerbib F, des Varannes SB, Ropert A, et al. Proximal gastric tone in gastro-oesophageal reflux disease. Eur J Gastroenterol Hepatol 1999:11:511-15.

7 Penagini R, Hebbard G, Horowitz M, et al. Motor function of the proximal stomach and visceral perception in gastro-oesophageal reflux disease. Gut 1998;42:251-7.

8 Vu MK, Straathof JWA, vd Schaar PJ, et al. Motor and sensory function of the proximal stomach in reflux disease and after laparoscopic Nissen fundoplication. Am J Gastroenterol 1999;94:1481-9.

9 McCallum RW, Berkowitz DM, Lerner E. Gastric emptying in patient with gastroesophageal reflux. Gastroenterology 1981;80:285-91.

10 Maddern GJ, Chatterton BE, Collins PJ, et al. Solid and liquid gastric emptying in patients with gastro-oesophageal reflux. Br J Surg 1985:72:344-7.

11 Tefera S, Gilja OH, Hatlebakk JG, et al. Gastric accomodation studied by ultrasonography in patients with reflux esophagitis. Dig Dis Sci 2001:46:618-25

12 Gilia $\mathbf{O H}$, Detmer PR, Jong JM, et al. Intragastric distribution and gastric emptying assessed by three-dimensional ultrasonography Gastroenterology 1997;1 13:38-49.

13 Hatlebakk JG, Berstad A, Carling L, et al. Lansoprazole versus omeprazole in short-term treatment of reflux oesophagitis. Scand J Gastroenterol 1993;28:224-8.

14 Berstad A, Olafsson S, Tefera S, et al. Bismuth therapy for Helicobacter pylori infection. A review of five years experience at a university hospital in Norway. J Physiol Pharmacol 1996;47:31-49.

15 Detmer PR, Bashein G, Hodges T, et al. 3D ultrasonic image feature localization based on magnetic scanhead tracking: in vitro calibration and validation. Ultrasound Med Biol 1994;20:923-36.

16 Hausken T, Berstad A. Wide gastric antrum in patients with non-ulcer dyspepsia. Effect of cisapride. Scand J Gastroenterol 1992;27:427-32.

17 Hausken T, Ødegaard S, Matre K, et al. Antroduodenal motility and movements of luminal contents studied by duplex sonography. Gastroenterology 1992;102:1583-90

18 Martens D, Hausken T, Gilja OH, et al. 3D processing of ultrasound images using a novel ECHOPAC-3D ${ }^{\circledR}$ software. Ultrasound Med Biol 1997:23(suppl 1):S136

19 Gilja OH, Smievoll Al, Thune N, et al. In vivo comparison of 3D ultrasonography and magnetic resonance imaging in volume estimation of human kidneys. Ultrasound Med Biol 1995;21:25-32.

20 Thune N, Gilja OH, Hausken T, et al. A practical method for estimating enclosed volumes using 3D ultrasound. Eur J Ultrasound 1996:3:83-92.

21 Kimmey MB, Martin RW, Haggitt RC, et al. Histologic correlated of gastrointestinal ultrasound images. Gastroenterology 1989;96:433-41.

22 Nyren O, Adami HO, Bates S, et al. Self-rating of pain in nonulcer dyspepsia. A methodological study comparing a new fixed-point scale and the visual analogue scale. J Clin Gastroenterol 1987:9:408-14.

23 Westblom TU, Madan E, Subik MA, et al. Double-blind randomized trial of bismuth subsalicylate and clindamycin for treatment of Helicobacter pylori infection. Scand J Gastroenterol 1992;27:249-52.

24 Petring OU, Sloth Madsen P. Experimental ischaemic tourniquet pain delays gastric emptying of semi-solids in healthy volunteers. Acta Anaesthesiol Scand 1991;35:293-6.

25 Bland JM, Altman DG. Statistical methods for assessing agreement between two methods of clinical measurements. Lancet 1986;1:307-10.

26 Ogilvie AL, James PD, Atkinson M. Impairment of vagal function in reflux oesophagitis. QJ Med 1985;213:61-74.

27 MacGregor I, Parent J, Meyer JH. Gastric emptying of liquid meals and pancreatic and biliary secretion after subtotal gastrectomy or truncal vagotomy and pyloroplasty in man. Gastroenterology 1977;72:195-205.

28 Lavigne ME, Wiley ZD, Martin P, et al. Gastric, pancreatic, and biliary secretion and the rate of gastric emptying after parietal cell vagotomy. Am J Surg 1979;138:644-51. 
29 Undeland KA, Hausken T, Svebak S, et al. Wide gastric antrum and low vagal tone in patients with diabetes mellitus type 1 compared to patients with functional dyspepsia and healthy individuals. Dig Dis Sci 1996:41:9-16

30 Troncon LEA, Bennett RJM, Ahluwalia NK, et al. Abnormal intragastric distribution of food during gastric emptying in functional dyspepsia patients. Gut 1994;35:327-32.

31 Distrutti E, Azpiroz F, Soldevilla A, et al. Gastric wall tension determines perception of gastric distention. Gastroenterology 1999;1 16:1035-42.

32 Mittal RK, McCallum RW. Characteristics and frequency of transient relaxations of the lower esophageal sphincter in patients with reflux esophagitis. Gastroenterology 1988;95:593-9.
33 Behar J, Ramsby G. Gastric emptying and antral motility in reflux esophagitis. Effect of oral metoclopramide. Gastroenterology 1987;74:253-6.

34 Hveem K, Jones K, Chatterton BE, et al. Scintigraphic and ultrasonographic measurment of the antral area-relationship to appetite. Gut 1996;38:816-21

35 Fishman EK, Magid D, Ney DR, et al. Three-dimensional imaging Radiology 1991;181:321-37

36 Matre K, Stokke EM, Martens D, et al. In vitro volume estimation of kidneys using three-dimensional ultrasonography and a position sensor. Eur J Ultrasound 1999;10:65-73.

\section{7th European Forum on Quality Improvement in Health Care}

We are delighted to announce this forthcoming conference to be held in Edinburgh, Scotland on 21-23 March 2002. Delegate enquiries are welcome.

The themes of the Forum are:

- Leadership, culture change, and change management

- Achieving radical improvement by redesigning care

- Health policy for lasting improvement in health care systems

- Patient safety

- Measurement for improvement, learning, and accountability

- Partnership with patients

- Professional quality: the foundation for improvement

- Continuous improvement in education and training

- People and improvement.

Presented to you by the BM Publishing Group (London, UK) and Institute for Healthcare Improvement (Boston, USA). For more information contact: quality@bma.org.uk or look at the website www.quality.bmipg.com. Tel: +44 (0)20 7383 6409; fax: +44 (0)20 7373 6869. 